\title{
DENNIS SCHELLER-BOLTZ
}

WU Uniwersytet Ekonomiczny w Wiedniu dennis.scheller-boltz@wu.ac.at

\section{Культурная специфика в русском языке - типы, явления, восприятие}

Каждому, кто когда-то изучал иностранный язык, знаком феномен культурной специфики. Уже на первых уроках встречаемся с разными культурно-обусловленными феноменами - иначе говоря, с особенностями, имеющими место исключительно в одном определенном культурном кругу. Уже на первых занятиях по русскому языку слышим такие наименования, как Москва, Красная площадь, Мавзолей, Дума, ГУМ, борщ. И непосредственно узнаем, что именно эти наименования принадлежат только русскому языку. Кроме того, однако, знаем, что соответствующие референты, т.е. обозначаемые этими наименованиями объекты, относятся исключительно к русской культуре, к России. Такие слова откладываются в голове как особенности русского языка и русской культуры и автоматически приписываем им определенную культурную специфику.

Тем не менее, нужно уточнить, что употребляемый в настоящей статье термин культурная специфика понимается и толкуется намного шире и разнообразнее. С одной стороны, невозможно, а с другой стороны, разумеется, несправедливо сводить этот термин к такому узкому пониманию, как было показано выше. Когда всесторонне рассматриваем язык, когда внимательно наблюдаем происходящие в нем процессы и изменения, когда отдаем себе отчет в том, как функционирует язык, как он пополняется и, что важнее всего, из чего состоит язык, тогда замечаем, что культурная специфика может быть расположена на разных уровнях и не может быть ограничена существующими в нашей реальности предметами, феноменами, лицами или признаками, которые встречаем в другой стране или в незнакомом нам культурном кругу, и которые в нашей повседневной жизни, в близком нам культурном кругу не существуют. 
Когда речь идет о культурной специфике, большинству носителей языка, особо не задумываясь, сразу приходят на ум достопримечательности, учреждения, должности, обстоятельства, сувениры - все типичные для данной страны и культуры предметы, обычаи, традиции, праздники, лица, блюда и т.д. А когда переносим это же понимание на сам язык, обычно понимаем под культурной спецификой (идиоматические) наименования (напр. область, кулич, самовар) или словосочетания (напр. Красная площадь, $\mathrm{He-}$ вский проспект, Большой театр, Алматинское озеро, Зеленьий базар). Они как часть словарного состава данного языка обозначают в соответствующей стране или культуре референты, которые в нашем собственном языке по причине отсутствия соответствующего референта не существуют и не служат номинативными единицамии.

Объекты, связанные с определенным культурным кругом и имеющие исключительно здесь свои функции и свой смысл, получают и развивают свои значения, включаются в некие (культурно-связанные) концепты и раскрывают, по этой причине, разные, в том политические, исторические, экономические, культурные, образовательные, социальные, общественные, традиционные и т. д., взаимосвязи - называем реалиями. А когда обращаемся к лексике, тогда замечаем, что в лексике культурная специфика имеет другое значение. Под культурно-обусловленной лексикой обычно понимаем различные номинативные единицы языка, которые обозначают культурно-специфические объекты разного характера. Следовательно, культурноспецифическая лексика охватывает такие номинативные единицы, которые обозначают реалии.

Такое понимание культурной специфики безусловно справедливо, но оно является слишком ограниченным подходом к этому феномену, ибо таким образом лексический диапазон специфических культурных явлений не отражается во всей полноте и разнообразии. Следовательно требуется расширение термина культурной специфики. Ведь культурную специфику может носить, без сомнения, само слово или словосочетание. Но обнаруживаем ее также на морфологическом и словообразовательном уровнях, в области прагматики и, в конце концов, по отношению к нормам употребления языка.

\section{Культурная специфика в лексике}

Обратим наше внимание сначала на культурную специфику в лексике, т.е., на словарный состав. Культурно-специфический характер носят номинативные единицы, именующие реалии, которые существуют в одной культуре, а в приведенной для сравнения культуре не существуют (напр. щи, селедка под шубой, хрущевка, коммуналка, область). В таких случаях имеем дело с «действительными» наименованиями реалий, для которых вследствие референциального дефицита, т.е. из-за отсутствия референ- 
та в целевой культуре, характерно отсутствие лексического эквивалента в целевом языке 1 В таких случаях возникает проблема правильного понимания. Ведь когда воспринимаем в общении культурно-специфическое наименование и не можем классифицировать и расшифровать его значение, потому что нам не знаком соответствующий референт, к которому оно относится, невозможно понять употребленное наименование. Возьмем прототипичный пример: хрущцевка. Его значение оказывается непрозрачным, ведь не зная семантическую структуру слова, понять его не сможем. Такие слова также не выявляют однозначную для нас мотивированность. Только знаем, что хрущзевка устанавливает связь с бывшим политиком Никитой Сергеевичем Хрущеевым, однако окончательное значение уловить и осознать нам не возможно. Культурно-обусловленные слова такого типа показывают семантическую инвариантность, поскольку они независимо от контекста и коммуникативной ситуации не меняют свое значение. Их значения являются константными. Понять значение таких слов можно только лишь тогда, когда сами феномены или объекты знакомы. Филлмор 2 убедительно показал в рамках своей когнитивной модели по семантике фреймов и сценариев (frame and scene semantics), что в голове человека сохранены разные виды и комплексы знания. И чтобы понять значение слов, нужно активировать сохраненную информацию. По отношению к приведенному примеру хрущевка это означает, что только тогда понимаем значение и можем себе представить соответствующий референт, когда мы знакомы с названным им референтом и прикрепленным к этому слову концептом. Даже когда заглядываем в толковые словари, например в Большой толковый словарь русского языка, изданный под редакцией С.А. Кузнецова ${ }^{3}$, мы, безусловно, улавливаем определенное значение, однако ясная, однозначная картина перед нашими глазами не открывается. Слово хрущевка объясняется как a) «блочно-панельный дом с небольшими квартирами» или б) «квартира в таком доме». Кроме того, в микроструктуру было включено добавочное примечание, освещающее культурные особенности: «строились в СССР в 50-60-е гг. во время правления Н.С. Хрущева с целью быстрого расселения коммунальных квартир, бараков». Словарь нам объясняет значения слова, однако, не имея представления об обозначаемом им референте, мы не в состоянии уловить полное значение.

Та же самая картина открывается, когда мы рассматриваем слово область. В толковом словаре С.А. Кузнецова находим дефиницию: «крупная административно-территориальная единица» ${ }^{4}$. Однако если нам не знакомы

${ }^{1}$ B. Svensén, A Handbook of Lexicography. The Theory and Practice of Dictionary-Making, Cambridge 2009, c. 271-273.

2 C.J. Fillmore, Scenes-and-frames semantics, [в:] Linguistic Structures Processing, ред. A. Zampolli, Amsterdam 1977, c. 55-81.

${ }^{3}$ С.А. Кузнецов, Большой толковый словарь русского языка, Санкт-Петербург 2000.

${ }^{4}$ Там же. 
административно-территориальные взаимосвязи между отдельными территориальными единицами России и не знаем, как область включается в общую административно-территориальную систему Российской Федерации, не сможем вопреки данной дефиниции до конца понять его значение. Более того, нам тяжело сравнить эту административно-территориальную единицу с существующими административно-территориальными единицами в любой другой стране; чтобы вследствие этого понять административно-территориальную систему Российской Федерации, чтобы таким образом уловить значение административно-территориальной единицы область в именно этой же системе и чтобы, в конце концов, обнаружить различия и сходства между территориальной системой Российской Федерации и страной, приведенной нами для сравнения. Ибо понять значение лексемы - это значит провести сравнение (напр. область - край), обнаружить взаимосвязи (напр. область, край, район, округ и т.д.) и таким способом получить представление о референте.

\section{Культурная специфика в ассоциациях}

Культурно-обусловленные особенности номинативных единиц, кроме того, открываются нам в таких случаях, когда они активируют у носителей родного языка ассоциации, которые их непосредственные эквиваленты в другом, приведенном для сравнения языке не вызывают. Носители других языков хоть и улавливают значение слова, однако, некоторые ассоциации остаются скрытыми, вследствие чего соответствующие концепты раскрываются не полностью, а только частично. В таких ситуациях могут, очевидно, произойти недоразумения. В качестве примера приводится слово пициа. Кажется, что это интернациональное блюдо на сегодняшний день общеизвестное. Однако пицца в российском обществе все еще нередко ассоциируется с майонезом, так как пицца без этой добавки часто считается слишком сухой. В отличие от этого, во многих, в том числе западноевропейских культурах майонез как добавка к пицце является как-то странной и необычайной начинкой, вызывающей удивление.

Посмотрим на дефиницию лексемы кафе у С.А. Кузнецова: «небольшой ресторан, где подают кофе, чай, закуски и т.п.» 5 . Однако и здесь важные для полного понимания значения лексемы ассоциации не находят отражение. В России понимают под кафе что-то подобное, но в то же время совсем другое, чем во многих других странах мира. Здесь мы снова имеем дело с одним референтом, причем прикрепленные к нему ассоциации по культурно-обусловленным причинам различаются. Ведь кафе в России функционирует как (маленький, простой) ресторан. В кафе пирожные часто играют лишь побочную роль. В кафе ходят прежде всего, чтобы подешевле пообедать

\footnotetext{
${ }^{5}$ Там же.
} 
или поужинать. В связи с этим стоит отметить, что в русской культуре питания суn имеет совершенно другой вес и иное значение, чем, например, в Германии. Различие находится не на уровне семантики, а поселяется на культурном уровне, так как в культуре питания в России суп имеет традиционно более важный статус и совершенно иную ценность. В России суп оказывается скорее обязательным блюдом, так что везде - в ресторане, в кафе, в столовой и т.д. - спрашивают первое блюдо.

Также при высказывании слова кофе у россиян возникают совсем другие ассоциации, чем у немцев. Это выясняется, когда в России, принимая заказ, для уточнения часто спрашивают: растворимый, фильтрованый или с эспрессо? Во многих западноевропейских странах пьют сегодня прежде всего кофе из кофеварки эспрессо, хотя фильтрованный кофе тоже еще распространен. Однако, растворимый кофе, по крайней мере в ресторане или баре, необычный напиток. А традиция употребления кофе в России начала распространяться только в последние годы, да и то не повсеместно.

Ассоциации являются важными, хотя и побочными компонентами значения, которые влияют на значение в целом, не в последнюю очередь потому, что они вызывают коннотации. По этой причине восприятие ассоциаций играет большую роль в процессе семантического декодирования. Ведь ассоциации ведут к некому предугадыванию и представлению. Так, имея представление «идти в кафе», некоторые иностранцы, наверное, будут разочарованы, потому что выбор пирожных может оказаться небольшим, или удивлены, что могут в кафе заказать горячие блюда. Наоборот россияне, наверное, будут расстроены, когда они в немецком кафе не смогут заказать горячее блюдо.

\section{Культурная специфика в морфологии и словообразования}

Стоит предположить, что и морфологические явления и словообразовательные процессы заключают в себе культурную специфику или по крайней мере культурно-обусловленную особенность, ибо словообразовательные процессы происходят с учетом морфологических критериев нередко по культурно-обусловленным образцам и представлениям. Следовательно, в области морфологии и словообразования наблюдаются не менее явные культурные феномены.

Бросается в глаза массовое и необозримое вторжение интернациональных словообразовательных единиц в русский язык особенно после 1990-х годов. В связи с этим непосредственно напрашивается вопрос, не имеет ли употребление таких единиц иногда культурно-обусловленный характер, особенно сравнивая их употребление в других языках. 
Приведем пример: лексический элемент с очень большой продуктивностью в русском языке - это нарко-. В немецком языке его продуктивность намного меньше, ведь здесь диатекстуальные и диатехнические рестрикции ограничивают употребление этой единицы ${ }^{6}$. В немецком языке, чтобы обозначить предмет или явление, употребляют иные лексические единицы, обходя корень нарко- (напр. русс. наркомафия - нем. Drogenmafia). В русском языке корень нарко- оказывается общеупотребительной и нейтральной единицей. Это также показывают определение этого корня у С.А. Кузнецова: «первая часть сложных слов обозначает отнесенность к наркотикам и наркомании» и приведенные примеры «наркобанда, наркоделец, наркодоллары, наркомир, наркопритон, наркоторговец» 7 . Нужно запомнить, что в немецком языке не употребляют идентичный интернациональный элемент narko- по морфопрагматическим, и вследствие этого морфокогнитивным причинам, ведь там этот элемент, не являясь стилистически нейтральной лексической единицей, имеет прагматическую и функционально-стилистическую окраску.

В немецком языке, наоборот, высокой продуктивностью отличаются элементы bio- и öko-, тогда как в русском языке употребление единиц биои эко- ограничено; следовательно они намного реже встречаются. Вместо этих единиц в русском языке употребляют другие номинативные единицы, нередко в форме словосочетаний. Интересный момент в этом отношении, не наблюдаемое различие в частоте, а некая культурная обусловленность этого различения: однозначно отличаются концепты, стоящие за единицами русс. био- / эко- и нем. bio- / öko-. Поскольку природа, климат, окружающая среда и их охрана, здоровье и питание занимают в Германии намного более высокую позицию в системе ценностей и, следовательно, имеют более значительный вес, чем в России, частота слов с корнями био- и эков немецком языке значительно превосходит количество и частоту сложений с био- и эко- в русском языке ${ }^{8}$.

Различие подобного рода невозможно установить из дефиниций в толковых словарях, так как в них не указывают ни на низкую частоту, ни на ограниченное употребление этих корней, однако в толковых словарях нет и информации о возможностях словоупотребления.

${ }^{6}$ D. Scheller-Boltz, Gemeinsamkeiten und Unterschiede im Gebrauch von Konfixen im Polnischen, Russischen und Deutschen. Translatorische Herausforderungen und lexikografische Aufgaben, [в:] Wenn die Ränder ins Zentrum drängen... Außenseiterin der Wortbildung(sforschung), ред. J. Born, W. Pöck1, Berlin 2013, с. 167-187.

${ }^{7}$ C.А. Кузнецов, Большой толковый словарь...

${ }^{8}$ D. Scheller-Boltz, Konfixkomposita im Polnischen und Deutschen. Einige Beobachtungen zur Wahrnehmung und Verwendung von bio- / eko- und bio- / öko-, [в:] Corpora und Canones. Schlesien und andere Räume in Sprache, Literatur und Wissenschaft, ред. M.K. Lasatowicz, A. Rudolph, Berlin 2013, c. 147-163. 
В заключение хотелось бы коротко сказать об интернациональном связанном корне евро-, который сегодня не только выступает как классифицируемая единица, но с которым мы встречаемся с 1990-х годов все сильнее в функции квалифицируемой словообразовательной единицы. Этот культурно-обусловленный феномен основывается на сложившемся в России, и кроме того во многих других странах СНГ, определенном концепте о Европе, отличающемся совершенно от концепта о Европе в остальных странах в Западной Европе. Европа носит в себе позитивную оценку и ассоциируется со статусом, престижем, высоким технологическим развитием и высококачественностью9. Вследствие этого единица евро- имеет культурно-обусловленную семему «современный», «развитый», «качественный», «престижный», «хорошо обставленный / оснащенный / меблированный / оборудованный» и прибавляет сложениям в зависимости от контекста такие специфические значения (напр. евробрюки, евродизайн, евроремонт, евростиль, евроклуб). Такое употребление и понимание корня евро- в толковых словарях не отображается, а содержится в имплицитном виде в отдельных приведенных в микроструктуре сложениях ${ }^{10}$.

\section{Культурная специфика в норме употребления языка}

Культурно-обусловленный характер могут иметь и выбор слова или словосочетания в конкретной ситуации общения, употребление слова или словосочетания в конкретном коммуникативном акте, а также сами нормы языкового употребления. Так, в России наблюдаются ситуации, в которых только при помощи выбора и выражения определенных слов или словосочетаний целенаправленно и функционально осуществляется межличностное общение, в то время как в немецком языке в тех же ситуациях конкретное высказывание отсутствует, ибо в именно таких ситуациях никакое выражение не произносится, так что коммуникативный акт не происходит (ср. Ha здоровье! (напр. кушай на здоровье), С легким паром!). В таких коммуникативных ситуациях наблюдаем в немецком языке нулевую эквивалентность. Бывают однако коммуникативные ситуации, в которых прибегают к совсем иным лексическим единицам, чем в русском языке (напр. Молодец! - нем. Super!, Toll!, Klasse!, Spitze!, Wunderbar! и т.п., Bcmpечаŭme! — нем. Einen großen Applaus..., Welcome on stage..., Jetzt auf der Bühne..., Heute zu Gast bei uns...). Здесь осуществляется коммуникативный акт и происходит межличностное общение при выборе и употреблении других слов-вариантов, зависимо от контекста и ситуации (варьируемая эквивалентность). Комму-

9 Е.А. Земская, Специфика семантики и комбинаторики производства слов-гибридов, [в:] Slavische Wortbildung: Semantik und Kombinatorik, ред. S. Mengel, Münster 2002, с. 164.

10 D. Scheller-Boltz, Gemeinsamkeiten und Unterschiede im Gebrauch von Konfixen im Polnischen, Russischen und Deutschen... 
никативные нормы и нормы употребления языка в целевом языке в таких случаях отличаются от норм в исходном языке ${ }^{11}$.

Культурно-обусловленное употребление языка и связанные с культурой языковые нормы могут быть продемонстрированы на нескольких примерах. Первым примером служит выражение Молодец!. С.А. Кузнецов определяет его значение следующим образом: «о том, чьи действия вызвали одобрение, удовлетворение у кого-либо» ${ }^{12}$. По этой дефиниции приблизительно понимаем лексическое значение лексемы молодец. Однако, никак не можем уловить и осознать ни коммуникативное значение лексемы, ни нормы и возможности ее употребления, ни ее целенаправленную функцию. Молодец! является контекстуально-ситуативным выражением и носит характер похвалы. В другом языке нам понадобится эквивалент, который исполняет идентичную функцию, ведь непосредственный эквивалент к выражению Молодец! вряд ли найдем (ср. англ. Good girl!, Good boy!, Good job!, Well done!, Excellent!, Brilliant!, Wonderful!). Молодеu!! это не только похвала или выражение похвалы. При помощи восклицания Молодец! мы обозначаем непосредственно человека, к которому мы обращаемся и который в именно этот момент совершил какую-либо акцию, которую нужно похвалить. А лицо, которое мы похвалили, высказав Молодец!, не только принимает эту похвалу, но может себя в этой ситуации идентифицировать как похвального человека (ср. англ. Good boy! / Good girl! в отличие от Great!, Super!, Marvellous!, Magnificent!).

Выражение Bcmpeчайте! на первый взгляд не дает повода предположить, что здесь имеет место культурно-обусловленное употребление лексемы. Однако в ситуациях, когда приглашают на сцену кого-либо (часто известного персонажа), нам открывается его функциональное употребление. Ведь радостно и задорно сказанный императив Bстречайте!, а также Bстречаем!, является страстным, энергичным побуждением и настойчивым приглашением зрителей интенсивно аплодировать (ср. англ. Welcome on stage...).

Переходим от отдельных слов к идиоматическим словосочетаниям. Идиоматическое выражение $C$ праздником! является неопределенным, общим типом поздравления, к которому можно прибегнуть в любой праздничный день. Следует понимать не только прямое значение идиомы, а также коммуникативную функцию и формы ее употребления. Во многих других языках такое абстрактное и неопределенное высказывание с одной стороны обусловлено лексическими рестрикциями невозможно (ср. нем. поздравление Frohes Fest, которое произносится исключительно на рождество), a с другой стороны в связи с культурной нормой неузуально. То же самое

${ }^{11}$ D. Scheller-Boltz, Qualitätsdimensionen zweisprachiger Wörterbücher im diachronen Vergleich - Oder: Was dürfen Übersetzer(innen) heute von einem zweisprachigen Wörterbuch erwarten?, [в:] Deutsche Beiträge zum 15. Internationalen Slavistenkongress Minsk 2013, ред. S. Kempgen и др., München-Berlin-Washington 2013, с. 263-272.

12 С.А. Кузнецов, Большой толковый словарь... 
касается произношения словосочетания на посошок во время распития последней порции напитка перед прощанием. Не каждый язык предоставляет в таких ситуациях соответствующий лексический материал, более того, не в каждой культуре такая ситуация сопровождается исполнением коммуникативного акта.

То же самое касается словосочетания на здоровье (ср. кушайте на здоровье; берите на здоровье). Оно является вежливым пожеланием при угощении или в ответ на благодарность за угощение ${ }^{13}$. В других языках такое выражение либо не произносится, либо в подобных ситуациях прибегают к другому лексическому материалу (ср. нем. Nehmen Sie sich bitte!, Essen Sie bitte!, Bedienen Sie sich bitte!).

В заключении приведем еще два интересных выражения, которые имеют свое происхождение из области кинематографии и изначально являются названиями фильмов. Однако вследствие их постоянного употребления в повседневной речи они вошли в общий литературный язык и отличаются по сей день огромной популярностью. Первым примером служит фразема с легким паром, имеющая свой источник в одноименном названии фильма Ирония cyдьбы, или С легким паром, снятым режиссером Эльдаром Рязановым в 1975 году. В русском литературном языке эта фразема употребляется после мытья в бане, в ванне и после принятия душа. Фразема С легким паром! выступает в качестве приветствия человека, который только что вымылся в бане, ванне или принял душ ${ }^{14}$, и не требует ответа со стороны коммуникативного партнера, к кому обращаются и к кому направляется высказанная фразема, то есть со стороны вымывшегося. В других языках в таких ситуациях коммуникативный акт не состоится, ведь в других культурных кругах поздравление с тем, что человек помылся, не является коммуникативной нормой. Здесь возникают не только трудности понимания или недоуверенности в употреблении фраземы, но и проблема правильного реагирования. Ведь не будучи знакомым с ситуативным употреблением фраземы, партнер по коммуникации чувствует себя неловко и не знает, как адекватно отреагировать, то есть, как адекватно ответить.

Подобным примером является фразема Здравствуйте, я ваша тетя!, иногда, когда обращаются к кому-либо на ты, выступающая в форме Здравствуй, я ваша тетя!. Эта фразема вошла в общеупотребительный язык и широко распространилась после выпуска фильма с одноименным названием Здравствуйте, я ваша тетя!, снятого режиссером Виктором Абросимовичем Титовым в 1975 году. Фразема служит шутливым выражением с иногда иронической окраской для выражения удивления, несогласия, насмешки по поводу чего-либо неожиданного ${ }^{15}$.

\footnotetext{
13 Там же.

14 Ср. там же.

15 Ср. там же.
} 
Главным аспектом в связи с упомянутыми фактами является то, что семантическое декодирование, то есть правильное понимание значения, происходит исключительно тогда, когда мы сохранили в голове необходимую культурную, обусловленную культурными концептами информацию, и когда мы знаем, как правильно употреблять и понимать фраземы и, кроме того, как на них реагировать. Ведь приходится признать: иногда нам нужно и, более того, хочется употреблять культурно-обусловленную лексику. Чаще, однако, нам нужно реагировать адекватным способом на высказанные культурные феномены. А правильная реакция принципиально предполагает правильное понимание.

\section{Заключение}

Как было показано выше, культурная специфика расположена на разных языковых уровнях. До сих пор всеобщим и доминирующим представлением было более узкое понимание культурной специфики, однако, такое понимание не предоставляет возможности раскрытия этого феномена и вследствие этого не допускает ни дифференцированного способа рассмотрения, ни различных методов изучения культурной специфики в целом.

В настоящей статье было проиллюстрировано, что культурная специфика характерна для лексики, однако кроме того, находится и на морфологическом, и словообразовательном уровнях. Наконец, наблюдаем культурную специфику и в нормах языкового употребления. Толковые словари не всегда предоставляют на этот счет достаточную информацию, ведь часто направленная на употребление культурно-обусловленных слов или словосочетаний информация, прагматические пометы и ситуативно-контекстуальные примечания словарем не отражаются.

\section{Culture-specific phenomena in Russian language - types, phenomena, perception}

Summary

When discussing culture-specific phenomena, most scholars typically refer to realia and lexical units of all kinds. This article, however, demonstrates that this focus is too narrow and that it is advisable to widen the range in the study of culture-specific phenomena. Such phenomena can be found in various areas, including semantics, morphology, and word formation. Moreover, norms concerning language usage can be shaped by cultural factors.

Keywords: culture-specific phenomena, realia, morphology, phraseology, dictionaries. 


\section{Specyfika kulturowa w języku rosyjskim — typy, zjawiska, postrzeganie}

\section{Streszczenie}

Specyfika kulturowa ujmuje ogólnie prawdziwe, typowe określenia realiów, czyli leksemy określające wszelkie obiekty różnego rodzaju, które istnieją tylko w jednej kulturze. W niniejszym artykule udało się udowodnić, że specyfikę kulturową należy rozumieć o wiele szerzej, bo dotyczy ona różnych płaszczyzn, więc inne zjawiska językowe wykazują również kulturowo specyficzne zaznaczenie. $Z$ tego powodu należałoby pożegnać się z dawnym wyobrażeniem o wąskim pojęciu specyfiki kulturowej, a na jego miejsce wprowadzić szersze rozumienie, aby móc przedstawiać jej całą różnorodność.

W artykule pokazano, że specyfika kulturowa może dotyczyć też asocjacji niektórych jednostek leksykalnych. Poza tym występuje ona na płaszczyźnie morfologicznej, a także słowotwórczej. Ponadto specyfikę kulturową można zaobserwować w uzusie językowym i może ona dotyczyć norm językowych. Słowniki bardzo rzadko przekazują niezbędne informacje wskazujące na specyfikę kulturową, w szczególności dane pragmatyczne. Brak takich ilustrujących informacji pozwala wyciągnąć wniosek, że słowniki nie dają użytkownikom ani orientacji co do kontekstu i specyfiki jednostek językowych, ani nie pomagają w używaniu jednostek językowych.

Stowa kluczowe: specyfika kulturowa, realia, frazema, morfologia, słowniki. 